EESTI NSV TEADUSTE AKADEEMIA TOIMETISED. 20. KOIDE KEEMIA * GEOLOOGIA. 1971, NR. 3

ИЗВЕСТИЯ АКАДЕМИИ НАУК ЭСТОНСКОИ ССР. ТОМ 20 ХиМИЯ * ГЕОЛОГИЯ. 1971, № 3

Удак $543.544 .41+662.74$

ЛНЛЬЯ ЛАХЕ, О. ЭИЗЕН

\title{
О СОСТАВЕ АРОМАТИЧЕСКИХ УГЛЕВОДОРОДОВ ГЕНЕРАТОРНОЙ СМОЛЫ
}

В настэящей работе прнводится анализ ароматических углеводородов генераторной смолы эстонского сланца с пределами кипения $191-301^{\circ} \mathrm{C}$, проведенный газохро. матографическими и каталитическими методами $\left[{ }^{1-7}\right]$. Групповой состав фракцин: генераторной смолы в ряде работ определялся хроматографическими методами $\left[{ }^{8-13}\right]$. Предлагается также газохроматографический анализ [ $\left.{ }^{14}\right]$.

\section{Экспериментальная часть}

Ароматические углеводороды были выделены из генератюрной смолық хроматографированием на силикагеле ШСК в колонках методом элюирования. Полученный концентрат ректифицировали в вакууме. Кривая ректификации и физические показатели фракций представлены на рис. 1 и в табл. 1. Более детально (для определения индивидуального состава).

Рис. 1. Кривая ректификации и физические показатели фракций ароматических углеводородов генераторной смолы.

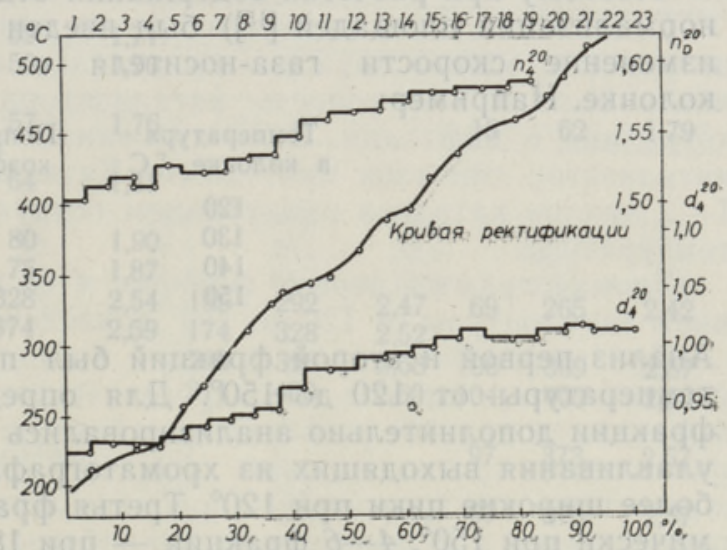

были исследованы фракции $1-7$, которые были проанализированы на газохроматографе «Хром-3» изотермически и с программированием температуры со скоростью повышения температуры $3^{\circ}$ в минуту. Для анализа использовалась колонка длиной 6 м, заполненная $15 \%$ полиэтиленгликоля 20000 на хромосорбе W (45-60 меш); скорость газа-носителя гелия, измеренная ротаметром, 30-35 мл/мин. При программировании температуры скорость газа-носителя уменьшалась, несмотря на то, что давление на входе в колонку повышалось. 
Таблица 1

Физические показатели фракции ароматических углеводородов генераторной смолы

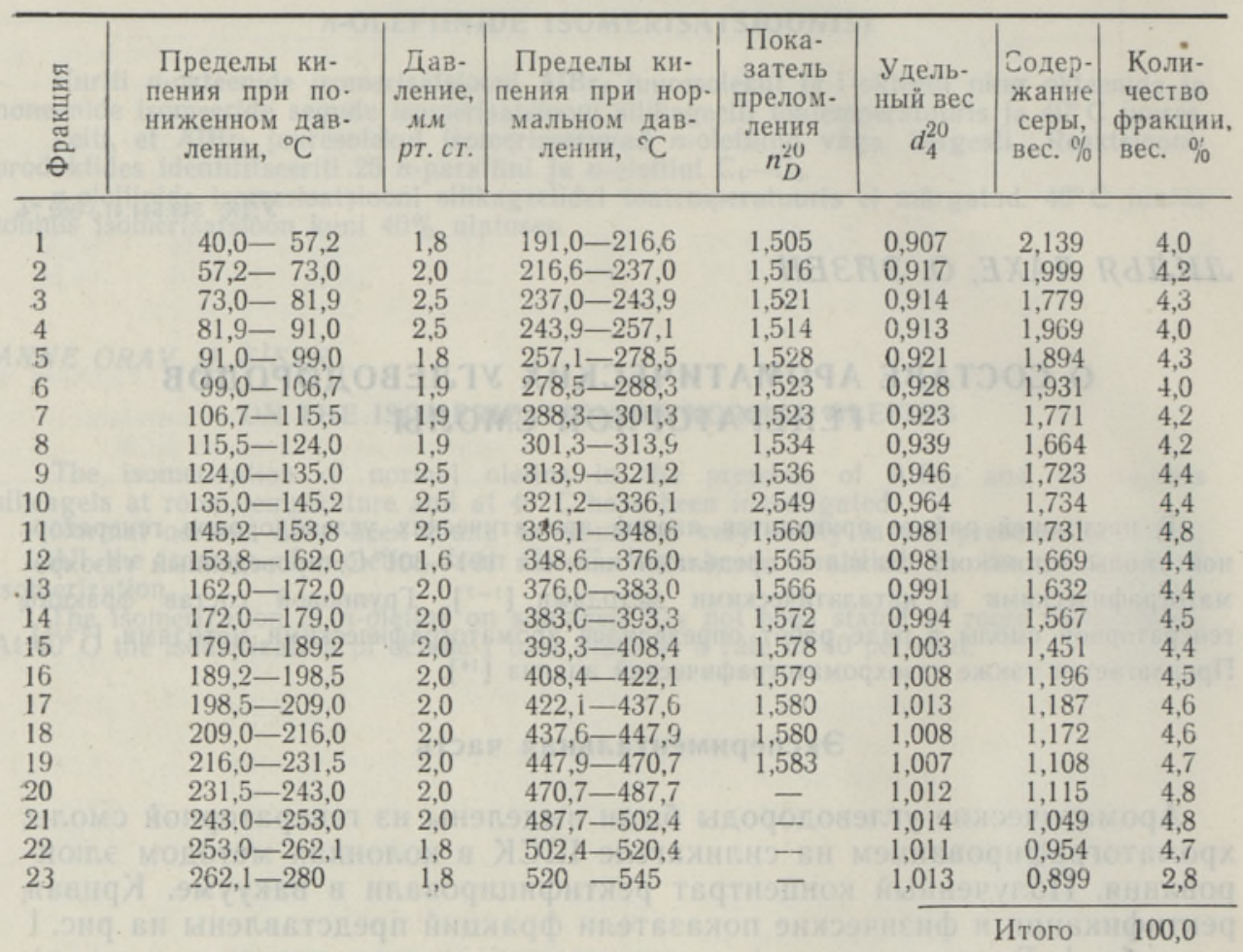

Поэтому при расчетах содержания отдельных компонентов (методом нормализации площадей [15]) был введен поправочный коэффициент на изменение скорости газа-носителя с повышением температуры в колонке. Например:

$\begin{array}{cc}\begin{array}{c}\text { Tемпература } \\ \text { в колонке, }\end{array} & \begin{array}{c}\text { Поправочный } \\ \text { коэффициент }\end{array} \\ 120 & 1 \\ 130 & 0,95 \\ 140 & 0,90 \\ 150 & 0,86\end{array}$

Анализ первой и второй фракций был проведен с программированием теміературы от 120 до $150^{\circ}$. Для определения времен удерживания фракции дополнительно анализировались изотермически при $150^{\circ}$, а для улавливания выходящих из хроматографа компонентов использовались более широкие пики при $120^{\circ}$. Третья фракция анализировалась изотермически при $150^{\circ}, 4-6$ фракции - при $180^{\circ}$ и 7 фракция при $200^{\circ}$.

Времена удерживания имеющихся эталонных веществ представлены в табл. 2. Зависимость логарифма относительных времен удерживания от температуры кипения компонентов приведена на рис. 2. Как из рис. 2 видно, парафиновые, олефиновые, моно- и бициклические ароматические углеводороды стоят довольно отдельными группами. Совпадение времен удерживания имело место при олефиновых и циклоолефиновых, алкилбензольных и индановых углеводородах. По температурам кипения фракций и по относительным временам удерживания для данной колонки можно в первом приближении судить о структуре компонента. 
Таблица 2

Времена удерживания эталонных веществ при различных температурах колонки

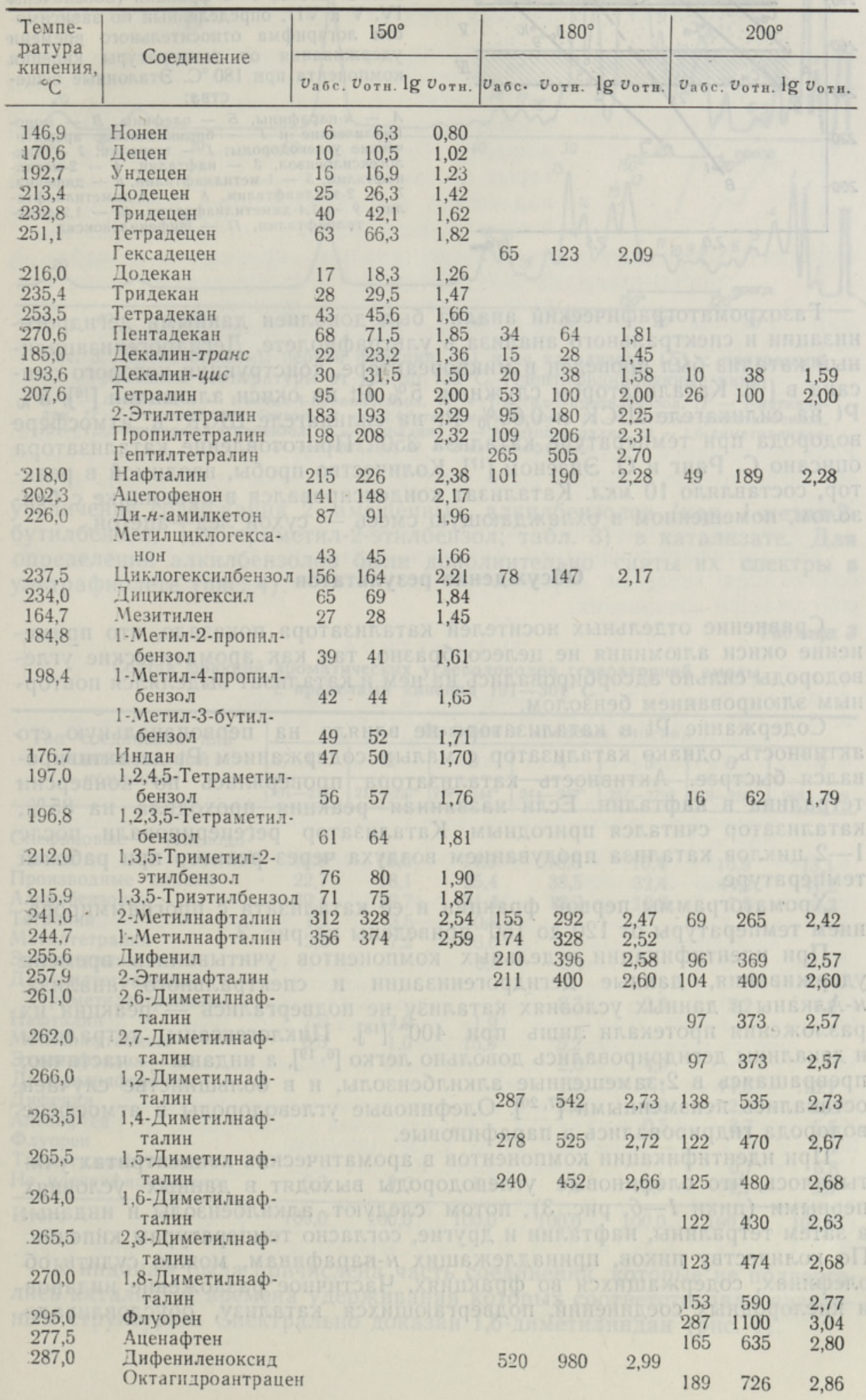

2 ENSV TA Toimetised $\mathrm{K} * \mathrm{G}-31971$ 


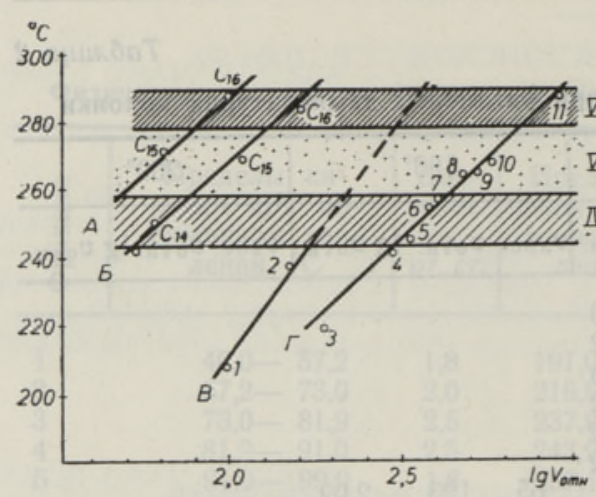

Рис. 2. Состав 4-6 фракций (обозначень IV, V и VI), определенный по зависимости логарифма относительного времени удерживания от температуры кипения компонента при $180^{\circ} \mathrm{C}$. Эталонные вещества:

$A-\mu$-парафнны, $B$ - олефины, $B$ - моно. циклические и $\Gamma-$ бициклические ароматнческие углеводороды; 1 - тетралин, 2 - циклогексилбензол, 3 - нафталин, 4 - 2-метилнафталин, 5 - 1-метилнафталин, 6 - дифенил, 7 - 2-этилнафталин, 8 - 1,5-диметнлнафталин, $9-1,4$-диметилнафталин, $10-1,2$-днметилнафталин, 11 - дифениленокснд.

Газохроматографический анализ был дополнен данными дегидрогенизации и спектрального анализа в ультрафиолете. Дегидрогенизационный катализ был проведен в микрореакторе, конструкция которого описана в $\left[{ }^{16}\right]$. Катализатором служили: $5 \%$ Pt на окиси алюминия $\left[{ }^{16}\right], 5 \%$ $\mathrm{Pt}$ на силикагеле ШСК и $0,65 \%$ Pt на силикагеле ШСК в атмосфере водорода при температуре катализа $350^{\circ}$. Приготовление катализатора описано С. Ранг и О. Эйзеном [17]. Количество пробы, вводимой в реактор, составляло 10 мкл. Катализат конденсировался в приемнике с бензолом, помещенном в охлаждающую смесь - сухой лед-ацетон.

\section{Обсуждение результатов}

Сравнение отдельных носителей катализатора показало, что применение окиси алюминия не целесообразно, так как ароматические углеводороды сильно адсорбировались на нем и катализат выделялся повторным элюированием бензолом.

Содержание $\mathrm{Pt}$ в катализаторе не влияло на первоначальную его активность, однако катализатор с малым содержанием Pt дезактивировался быстрее. Активность катализатора проверялась по конверсии тетралина в нафталин. Если названная реакция проходила на $85 \%$, катализатор считался пригодным. Катализатор регенерировали после: $1-2$ циклов катализа продуванием воздуха через реактор при рабочей температуре.

Хрома гограммы первой фракции и ее катализата с программированием температуры от 120 до $150^{\circ}$ приведены на рис. 3 .

При идентификации отдельных компонентов учитывались времена удерживания, данные дегидрогенизации и спектрального анализа. н-Алканы в данных условиях катализу не подвергались - реакции их разложения протекали лишь при $400^{\circ}\left[{ }^{18}\right]$. Циклогексаны, тетралинь и декалины дегидрировались довольно легко [ ${ }^{6,19]}$, а инданы - частично, преврашаясь в 2-замещенные алкилбензолы, и в большинстве случаев оставались неизменными [7,20]. Олефиновые углеводороды в атмосфере водорода гидрировались в парафиновые.

При идентификации компонентов в ароматических концентратах учитывалось, что олефиновые углеводороды выходят в данных условиях первыми (пики $1-6$, рис. 3), потом следуют алкилбензолы и инданы, а затем тетралины, нафталин и другие, согласно температурам кипения. По количеству пиков, принадлежащих н-карафинам, можно судить об олефинах, содержащихся во фракциях. Частичное разложение инданов и кислородных соединений, подвергающихся катализу, обусловливало. 


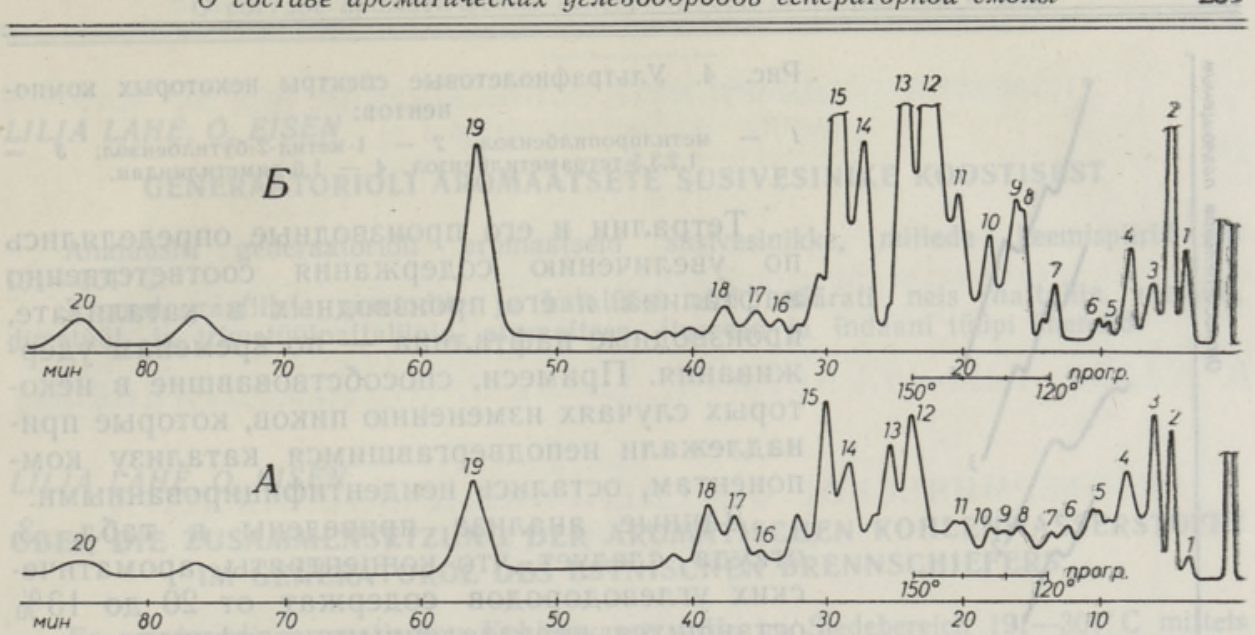

Рис. 3. Хроматограммы первой фракции $(A)$ и єе катализата $($ Б) с программированием температуры от 120 до $150^{\circ} \mathrm{C}$. Идентифицированные пики:

1 -8 - олефины, 9 - 1-метил-4-пропилбензол, $10-1$-метил-2-пропилбензол, 11 - 1-метилиндан, 12 - 1-метил-2-бутилбензол, $13-1,2,4,5$-тетраметилбензол, $14-1,2,3,5$-тетраметилбензол, $15-1,3,5$-триметил-2-этилбензол, 16 - тетралин, $17-2$-метилтетралин, $18-1,6$-диметилиндан, $19-$ нафталин, $20-2$-метилнафталин.

увеличение содержания 2-замещенных алкилбензолов (как, 1-метил-2бутилбензол, 1,3,5-триметил-2-этилбензол; табл. 3) в катализате. Для определения алкилбензолов были дополнительно сняты их спектры в ультрафиолете (рис. 4).

Таблица 3

Состав фракций ароматических углеводородов генераторной смолы с пределами кипения $191-301^{\circ} \mathrm{C}$

\begin{tabular}{|c|c|c|c|c|c|c|c|}
\hline \multirow{3}{*}{$\begin{array}{c}\text { Тип соединения или } \\
\text { индивидуальный } \\
\text { компонент }\end{array}$} & \multicolumn{7}{|c|}{ Фракции и иределы кишения } \\
\hline & 1 & 2 & 3 & 4 & 5 & 6 & 7 \\
\hline & $191-217^{\circ}$ & $217-237^{\circ}$ & $237-244^{\circ}$ & $244-257^{\circ}$ & $257-279^{\circ}$ & $279-288^{\circ}$ & $288-301^{\circ}$ \\
\hline $\begin{array}{l}\text { лефиновые углеводо- } \\
\text { роды }\end{array}$ & 19,9 & 16,0 & 14, & 18, & 10,4 & 16.9 & \\
\hline Производные индана & 22,7 & 18,1 & & 38 & & 4,2 & \\
\hline b & 39,4 & 29,7 & 31,4 & 13,7 & 13,9 & 7,8 & 4,3 \\
\hline 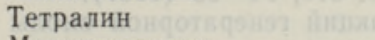 & 1,3 & 3,5 & 0,6 & 10625 & & $210.012=$ & \\
\hline ітетралин & 2,6 & 7,2 & 6,6 & & & fintrate & \\
\hline етралин & 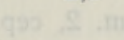 & 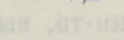 & 0,8 & 0,1 & 7 & .7 .0 & \\
\hline Диметилте & 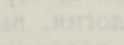 & 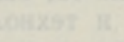 & a & & & & \\
\hline етралины) & & & & 8,3 & 2,9 & 5,2 & 4,2 \\
\hline $\begin{array}{l}\text { Нафталин } \\
\text { Метилнафталины }\end{array}$ & 7,5 & 14,9 & & & & 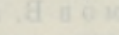 & $4 x^{2}$ \\
\hline Метилнафталины & 0,3 & 1.0 & 15,5 & 5 , & & 15978 & 107 \\
\hline Этилнафталин & 000 & 071 artuty & 1) & 2,6 & 4,9 & (6) 5. & 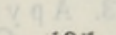 \\
\hline $\begin{array}{l}\text { Диметилнафталины } \\
\text { Дифенил }\end{array}$ & & & & & 17,1 & 14,6 & 10,1 \\
\hline $\begin{array}{l}\text { Дифенил } \\
\text { Ащенафтен }\end{array}$ & th & 78 & 6.09 & 2,2 & 4,2 & 2,8 & 4,2 \\
\hline $\begin{array}{l}\text { Аценафтен } \\
\text { Флуорен }\end{array}$ & & 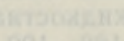 & 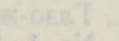 & & 0,5 & 3,7 & 5,5 \\
\hline $\begin{array}{l}\Phi л \\
\mathrm{Tp}\end{array}$ & & & & & & 0 & 1,1 \\
\hline Не идентифицировано & 6,3 & 9,6 & 5,1 & 9,5 & 13,7 & 4,1 & 9,5 \\
\hline Итого & 100,0 & 100,0 & 100,0 & 100,0 & 100,0 & 100,0 & 100,0 \\
\hline
\end{tabular}

К инданам была причислена часть соединений, которые не подвергались катализу и времена удерживания которых соответствовали названным структурам. Спектрально доказан 1,6-диметилиндан (рис. 4). 


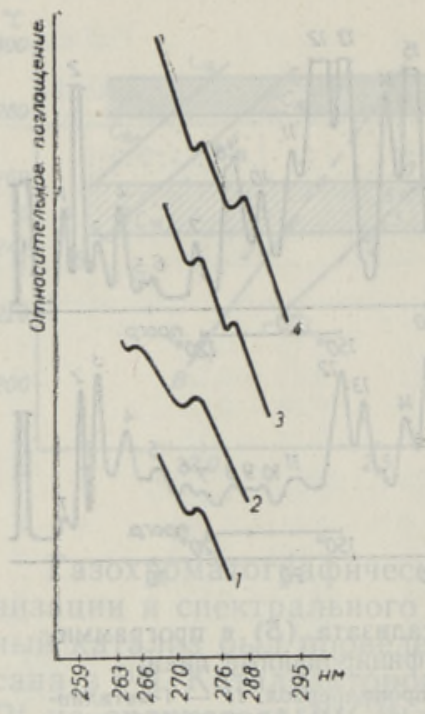

Рис. 4. Ультрафиолетовые спектры некоторых компонентов:

1 - метилпропилбензол, 2 - 1-метнл-2-бутилбензол, 3 1,2,3,5-тетраметилбензол, 4 - 1,6-диметилиндан.

Тетралин и его производные определялись по увеличению содержания соответственно нафталина и его производных в катализате, производные нафталина - по временам удерживания. Примеси, способствовавшие в некоторых случаях изменению пиков, которые принадлежали неподвергавшимся катализу компонентам, остались неидентифицированными.

Данные анализа приведены в табл. 3, откуда следует, что концентраты ароматических углеводородов содержат от 20 до $13 \%$ оставшихся неразделенными олефинов.

Среди ароматических структур значитель ное место занимают соединения с индановыми кольцами, число которых увеличивается с повышением температуры кипения фракций. Если содержание алкилбензолов в пределах $191-244^{\circ}$ составляет около $40-30 \%$, то для фракции выше $244^{\circ}$ алкилбензолы уже менее характерны.

Производные нафталина изучены более детально.

Неидентифицированными остались фракции $(4,1-13,7 \%$; табл. 3), содержащие главным образом не отделенные от ароматики кислородсодержащие соединения.

\section{Л И ТЕ РА Т У РА}

I. Martin R. L., Winters J. C., Analyt. Chem., 35, Nr. 12, 1930 (1963).

2. Will is D on a 1 d E. S., J. Chromatogr., 30, Nr. 1, 86 (1967).

3. Schwartz R. D., Mathews P. G., Brasseaux D. J., Advances in Gas Chromatography, Evanston, Illinois, 1967, p. 85.

4. Ch a n g Ta-Chuang Lo, K a r r Clarence Jr., Analyt. chim. acta, 21, No. 5, 474-190 (1959).

5. Л андсберг Г. С., К а зан ск и й Б. А. и др., Определение индивидуального углеводородного состава бензинов прямой гонки комбинированным методом, М., 1959 , с. 77.

6. Р а н г С., Э й з ен О., С а луу с т е С., Р ей м а н И., Изв. АН ЭССР, Хим. Геол., 17, № 3, 236-241 (1968).

7. A $11 \mathrm{am}$ M. T., Gerritsen A. W., J. Inst. Petrol., 53, No. 518, 94-99 (1967).

8. Х юс се Ю. Ю., Химическая характеристика высших фракций генераторной смолы лрибалтийского сланца, Тарту, 1949.

9. Эй зен О. Г., Тр. Таллинск. политехн. ин-та, вып. 2, сер. А, № 63, 82 (1955).

I0. Э й з н Н О. Г., Горючие сланщы. Химия и технология, вып. 4, 213-229 (1961).

II. $Э$ й з ен О. Г., А р р о И. Х., Химия и технология топлив и масел, № 11, 39 (1957).

12. Е фи м о В В.М., Пи й к Э. Э., С оо М. О., В а х е р Д. Х., Добыча и переработка горючих сланцев, вып. 18, 37-44 (1969).

13. А р у м е е л Э. Х., П и й к Э. Э., Тр. н.-и. ин-та по добыче и переработке сланцев Эст. ССР, вып. 14, 217-224 (1965).

14. Д ем 6 о в ск а я Е. А., Химия и технология топлив и масел, № 9, 60-62 (1966).

15. Н ог а е С. Д., Д жу ве т Р. С., Газо-жидкостная хроматография, Л., 1966, с. 279.

16. $\mathrm{N}$ i g a m I. C., J. Chromatogr., 24, Nr. 1, 188-192 (1966),

17. Р анг С., Эй зен О., Кунинга К., Изв. АН ЭССР, Хим. Геол., 17, № 3, 217$223(1968)$.

18. Р ан г С., Эй зен Н., Изв. АН ЭССР, Хим. Геол., 17, № 4, 341-345 (1968).

19. Э й з е н О., Изв. АН ЭССР, Сер. физ,-матем, и техн. наук, 12, № 4, 434-437 (1963).

20. С а л у с т е С., К л е с м е н Т И., Э й з е н О., Изв. АН ЭССР, Сер. фнз.-матем. и техн. наук, 14, № 4, 605-613 (1965). 
LILJA LAHE, O. EISEN

\section{GENERAATORIOLI AROMAATSETE SUSIVESINIKE KOOSTISEST}

Analüüsiti generaatoriōli aromaatseid süsivesinikke, millede keemispiirid on $191-301^{\circ} \mathrm{C}$.

Kromatograafiliste meetodite ja katalüüsi abil määrati neis naftaliin, metūüldimetüül- ja trimetüülnaftaliinid, atsenafteen, fluoreen ja indaani tüüpi ühendid.

\section{LILJA LAHE, O. EISEN}

\section{UBER DIE ZUSAMMENSETZUNG DER AROMATISCHEN KOHLENWASSERSTOFFE IM GENERATOROLL DES ESTNISCHEN BRENNSCHIEFERS}

Es wurden die aromatischen Kohlenwasserstoffe im Siedebereich $191-301^{\circ} \mathrm{C}$ mittels chromatographischer Methoden und Katalyse analysiert. Von aromatischen Strukturen wurden Indane, Naphthaline, Methyl- und Dimethylnaphthaline, Acenaphthen und Fluorea festgestellt. 